\title{
Treatment outcome of tuberculosis patients at Adare general Hospital, Hawassa, Southern Ethiopia. (A five year retrospective study)
}

\section{Bezunesh Tsegaye}

Sidama Zone education office

\section{Zufan Bedewi}

Hawassa University College of Natural and Computational Science

Solomon Lemma Asnake ( $\boldsymbol{\sim}$ asnakesol@yahoo.com )

Hawassa University College of Medicine and Health Sciences https://orcid.org/0000-0002-3284-3323

\section{Research article}

Keywords: TB treatment outcome, Tuberculosis, DOTS, Treatment success rate

Posted Date: April 17th, 2019

DOI: https://doi.org/10.21203/rs.2.9233/v1

License: (c) (1) This work is licensed under a Creative Commons Attribution 4.0 International License. Read Full License 


\section{Abstract}

Background Globally still Tuberculosis remains a major public health problems and socio-economic issue in the 21st century. Ethiopia is among the countries most heavily affected by Tuberculosis, where it is the leading cause of morbidity, the third cause of hospital admission and the second cause of death. To improve Tuberculosis management and control, early detection of cases, effective treatment and persistent evaluation of treatment outcome are vital issues that should be taken into consideration. Hence, this study was designed to determine treatment outcomes and associated risk factors among TB patients registered and receiving anti-TB treatment at Adare general Hospital, Southern Ethiopia. Methods A five years retrospective study was conducted by reviewing medical records of TB patients at Adare general Hospital. A total of 1151 Tuberculosis patients' cards registered from (September 2013 to August 2017) for treatment at TB clinic were reviewed. Data was coded, cleaned and entered into Microsoft Excel sheet then ported and analyzed using SPSS version 20 statistical soft ware. Logistic regression with odds ratios (OR) along with the $95 \%$ confidence interval was computed and interpreted. A P value $<0.05$ was declared as statistically significant. Result Among 1122 cases 620 (55.3\%) were male, 748(66.7\%) were from urban areas, 319 (28.4\%) were smear positive, 352 (31.4\%) were smear negative and $451(40.2 \%)$ were extra pulmonary patients. Of the $1122284(25.3 \%)$ were cured, 753(67.1\%) completed treatment, 29(2.6\%) defaulted, 53(4.7\%) died and 3 $(0.3 \%)$ had treatment failure. The mean treatment success rate was $92.4 \%$. The risk of unsuccessful TB treatment outcome was significantly higher among TB patients from rural areas (AOR $=0.43,95 \% \mathrm{Cl}$ : 0.27 , 0.67); patients with extra pulmonary $\mathrm{TB}(\mathrm{AOR}=0.87,95 \% \mathrm{Cl} ; 0.67,1.14)$, and HIV positive TB patients (AOR $=$ $5.47,95 \% \mathrm{Cl} ; 3.47,8.63$ ) were more likely to have poor treatment outcomes as compared to their counter parts. Conclusion The treatment success rates of Tuberculosis, at Adare hospital was comparable to national health facility level coverage, but it should be maintained and strengthen further to attain tuberculosis related national and millennium goal.

\section{Background}

Tuberculosis is a communicable disease that caused by Mycobacterium Tuberculosis, which mainly affect the lung and causespulmonary tuberculosis or other organsand causesextra pulmonary tuberculosis[1]. It is a major public health problem in the world being among the ten top leading diseases that cause death [2]. As to WHO report, 2017, about 10 million people were infected and 1.6 million died due to TB [3]. About $56 \%$ cases were from South-East Asia and Western Pacific Regions and 29\% cases were from Africa where the highest rate of death occur [4].

Among 30 high TB burden countries in the world, Ethiopia ranks seventh and theestimated TB prevalence rate in the country was $27 / 1000000$ population with an estimated incidence rate of 224 per 100,000 population [3]. Annually there are an estimated 5000 or more MDR-TB cases, hence as to the report of WHO among 27 high MDR-TB burned countries, Ethiopia was placed at rank of fifteenth [5]. The health Minister of the country indicated that disease was the leading cause of morbidity, the third leading cause of hospital admission, and the second cause of death [6]. The globally accepted TB intervention strategy was Directly Observed Treatment Short Course (DOTS). Since, 1992 DOTS strategy was started as a pilot in Ethiopia and then scaled up and implemented at national level [6]. Then after all public, private and non-governmental health facilities 
provide the service [7]. As various studies conducted in different health institutions in the country indicated the treatment outcome showed increment after the delivery of DOTS services[8-12], though other studies indicated presence of various challenges $[13,14]$. Adare General Hospital implemented DOTS strategy starting national scale up period, however the institutional status of treatment outcome and associated challenges were not studied so far. Therefore, this retrospective study was aimed to assess the treatment outcome of TB patients and identify factors associated with unsuccessful outcome in Adare general Hospital, southern Ethiopia.

\section{Methods}

\section{Description of the study area}

Hawassa, the capital city of South Nations Nationalities and People Region State (SNNPRS) is located about $275 \mathrm{~km}$ South of Addis Abeba. Geographically it lies at $705^{\prime}$ latitude $\mathrm{N}$ and $38029^{\prime}$ Longitude $\mathrm{E}$ at an altitude of 1708 masl (meter above sea level). The mean annual rainfall and temperature of the area varies from 800$1000 \mathrm{~mm}$ and 20.10c-250c respectively (Fig. 1). Based on 2007 national population and housing census Hawassa town has 329,734 inhabitants, of whom, 169, 677 were males and 160, 057 were females. Adare general Hospital is located at the center of the city and has 70 functional beds. The hospital has one DOTS clinic that performing as per National TB and Leprosy Control Program (NTLCP) guideline of Ethiopia. The clinic provides basic treatment and diagnostic service for all forms of TB through clinical examination, ZiehlNielsen staining method or sputum smears examination and chest radiographs. Patients diagnosed with TB were registered and treated according to the national TLCP guideline [6].

\section{Study Design, Period, and Data Collection}

Institutional based retrospective study was conducted from April to May2018 by reviewing registration book of tuberculosis patients registered and treated from 2013-2017 at DOTS clinic of Adare Hospital. Registered data with complete information were collected retrospectively by trained health professionals using a structured checklist and used as a source of data for the investigation. The basic required information such as patient's sex, age,the address of patients, date of treatment started, date of treatment completed, HIV serostatus, type of TB cases, and treatment outcome.

\section{Data processing and analysis}

Data were entered into Microsoft Excel sheet cleaned and then ported and analyzed using SPSS version 20 statistical soft ware. Frequency and percentage of data was determined using descriptive statistics. To check the significant association Bivariate and multivariate analysis were done to analyze whether there is association between the TB treatment outcomes and independent variables. Crude and adjusted odd ratio were computedandused to see the strength of association. $\mathrm{P}<0.05$ was considered as statistically significant.

\section{Operational Definition}


The following clinicalcase and treatment outcome operational terms were used in this article based on standard definitions NLCP adopted from WHO[6]

Smear-positive pulmonary TB (PTB+): A patient with at least two sputum specimenswhich were positive for acid fast bacilli (AFB) by microscopy, or a patient with only one sputumspecimen which was positive for AFB by microscopy, and chest radiographic abnormalitiesconsistent with active PTB.

Smear-negative pulmonary TB (PTB-): A patient with symptoms suggestive of TB, withat least two sputum specimens which were negative for AFB by microscopy, and with chestradiographic abnormalities consistent with active PTB, or a patient with two sets of at least twosputum specimens taken at least two weeks apart, and which were negative for AFB by microscopy,and radiographic abnormalities consistent with PTB and lack of clinical response to oneweek of broad spectrum antibiotic therapy.

Extra pulmonary TB (EPTB): This included TB of organs other than the lungs, such aslymph nodes, abdomen, genitourinary tract, skin, joints and bones, the meninges and others.Diagnosis of EPTB was based on fine needle aspiration cytology or biochemical analyses ofcerebrospinal/pleural/ascitic fluid or histopathological examination or strong clinical evidenceconsistent with active EPTB, followed by a decision of a clinician to treat with a full course ofanti-TB chemotherapy. In all the cases of EPTB, sputum examinations and chest radiographswere used to rule out involvement of the lung parenchyma. This hospital lacks the facilities forculture and drug susceptibility testing.

\section{Categories of treatment outcomes}

Successful outcome: If TB patients were cured (negative smear microscopy at the end oftreatment and on at least one previous follow-up test) or completed treatment with resolutionof symptoms.

Unsuccessful outcome: If treatment resulted in treatment failure (remaining smear-positiveafter 5 months of treatment), defaulted (patients who interrupted their treatment for twoconsecutive months or more after registration), or died.

\section{Result}

\section{Socio-demographic and clinical characteristics of the patients}

A total of 1151 tuberculosis patients were registered in the TB registrar unit of the hospital, of which 1122 $(97.5 \%)$ tuberculosis cases had complete records on the treatment outcome. Among the total registered TB patients with complete record $(n=1122), 620(55.3 \%)$ were males and $66.7 \%(n=748)$ of the patients were urban residents. Majority of the cases were in the age group of 15-34 690 (61.5\%), children less than 14 accounts for $9 \%$. Smear positive (PTB+), smear negative (PTB-) and extra pulmonary TB (EPTB) cases were $319(28.4 \%), 352(31.4 \%)$ and $451(40.2 \%)$ respectively. Most of the TB patients were new $1064(94.8 \%)$, while relapse, transfer in and treatment after failure accounts for $48(4.3 \%), 8(0.7 \%)$ and $2(0.2 \%)$ respectively. All of the registered cases for anti-TB treatment were tested for HIV voluntarily and $238(21.2 \%)$ of the study participants were HIV positive (Table 1). 


\section{Treatment outcome of the participants}

The treatment outcome of most study participants was successful $753(67.1 \%)$ completed their anti-TB treatment and $284(25.3 \%)$ cured. Treatment failure, died and defaulter were $3(0.3 \%), 53(4.7 \%)$, and 29 (2.6\%), respectively. We excluded 29 TB patients (transferred out cases) from the treatment success rate analysis, since the status of the patients is not known. Majority of treatment failure and defaulter were observed in the age of 45-54 and 55-64 respectively, and the high rates of deaths (15\%) were registered among HIV/TB co-infected patients (Table 2).

\section{Treatment outcome of TB and its trend}

We analyzed treatment outcome of 1122 tuberculosis patients who were registered at the hospital during the study period, January 2013 to December 2017. The death rate, defaulters and fallers rate of tuberculosis patients showed increment from 2013 to 2017, though death rate seems stagnant in 2013 and 2014. In general the unsuccessful (poor treatment outcome) rate increased from 2014 to 2017 (3 to 12.8\%). The cure rateof the TB patients increased year to year from 2013 to 2017, though it decreased in 2015. Treatment complete rate of the patients decreased from 2013 to 2017. The success rate of the TB patients decreased from 2013 to 2017, though the overall five-year treatment success rate of the TB patients was 1037 (92.4\%) (Table3).

\section{Treatmentsuccess rate and its associated factors}

The treatment success rate was $(51 \%)$ in males and $(41.4 \%)$ in females. Majorities $(63 \%)$ of the patients with successful (favorable) outcome were urban residentsand (29.4\%) were rural residents. The treatment success rates were $37.3 \%, 29.2 \%$ and $25.9 \%$ among EPTB, PTB- and PTB+ patients, respectively. The success rate among new and relapse cases was (88.6\%) and (3.8\%) respectively. In addition, high treatment success rate were observed among TB patients of age 0-14 and $45-54$ years.

Logistic regression analysis was performed to identify independent predictors of treatment outcome among TB patients (Table 4). Six explanatory variables that were associated with treatment outcome in bivariate analyses at 0.2 level of significance were entered into multiple logistic regression model, in the last step of analysis, three variables residence, HIV status and type of TB of the patients showed significant association with treatment outcomeat $P<0.05$. Accordingly as the adjusted odds ratio result indicated the risk of unsuccessful TB treatment outcome was significantly higher among TB patients from rural areas (AOR = $0.43,95 \% \mathrm{Cl}: 0.27,0.67)$ compared to their counterparts. Those patients with extra pulmonary TB (EPTB) were more likely to have poor treatment outcomes as compared to patients with smear positive (PTB+) and smear negative (PTB-) (AOR $=0.87,95 \% \mathrm{Cl} ; 0.67,1.14)$. In addition, HIV positive TB patients were also more likely to develop risk of poor treatment outcomes as compared to their counterparts ( $A O R=5.48,95 \% \mathrm{Cl} ; 3.47,8.63)$.

\section{Discussion}

In this study Males account for more than half of the study participants, correspondingly studies conducted in different health institutions in the county also indicated that more males were involved $[15,16]$. However 
finding from studies conducted in Gambella [17] and Raya Kobo [18] were in contrast.Most (83.4\%)of the study participants were 15-54 years old, WHO also reported that the productive age was more affected by Tuberculosis and associated morbidity and mortality [19]. The situation might have negative impact on the economic and social development of the community and the nation at large. In present study majority 671 (59.8\%) were pulmonary TB patients, and 451 (40.2\%) were extra pulmonary TB patients and as to the TB profile data high proportions of TB patients were EPTB and smear negative PTB, which is comparable to other TB profile data in the country [15, 20-23].

The treatment success rate was $92.4 \%$, which islower than the success rate $(94.8 \%)$ report from northwest Ethiopia[22]. However, it was higher than the report from Tigray, Northern Ethiopia, (89.2\%) [21], Gambella, Western Ethiopia (86.1\%) [17], Dilla, Southern Ethiopia (85.3\%) [15],NekemteWestern Ethiopia (70.8\%) [24] and Hossana,South Ethiopia (43.3\%) [25]. The unsuccessful TB treatment outcome rate was $7.6 \%$, the finding is lower than unsuccessful treatment outcome reported fromDilla14.7\% [15], Gambella 13.9\% [17] and Tigray $10.8 \%$ [21]. This could be associated with differences in socio-demographic characteristics of the patient, appropriateness of the institutional setup, follow-up and counseling of patients in DOTS clinics, and knowledge and attitude towards and side-effect due to DOTS [26].

The death rate (4.7\%) was lower than that reported from Ethiopia(5\%) [18], Nigeria (6.5\%) [27] and Zimbabwe $(8.7 \%)$ [28]. However, the finding was higher than the death rate reported fromEthiopia(3\% and 3.4\%) [25, 15], Turkey (2.4\%) [29] and Brazil (2.8\%) [30]. The default rate in this study was (2.6\%), which might be due to a better supervision and health education activities. The finding was lower than the studies conducted in Ethiopia (3.2\%, 8\% and 11.1\%) [21, 32, 15], Uzbekistan (6\%) [31], Turkey (3.9\%) [29] andNigeria (9.8\%) [27].

Treatment failure rate $0.3 \%$ was in consistent with the rate of reported from other study in Ethiopia (0.3\%) [15], and higher than treatment failure rate in Malaysia (0.2\%) [33]. Nonethelessthe rate observed in this study was lower than that of the finding from Ethiopia (0.5, 2.2\%, and 3.7\%) [25, 18, 21], Uzbekistan (3\%) [31], Turkey (1.1\%) [29], Brazil (2.1\%) [30] and Nigeria (1.5\%) [27].The overall TB-HIV co infection rate was $21.2 \%$, which was lower than studies conducted inGonder,North west Ethiopia (52.1\%) [10] and Gambella region (26.12\%) [17]. However, it was higher than (12.7\%) Debre Tabor, Northwest Ethiopia [34], (16.5\%) Hossana, Southern Ethiopia [25], (11.7\%) Gojam,Northwest Ethiopia [22] and (17.1\%) Nekemte, Western Ethiopia [24].

There present study indicated the presence of association between treatment outcome and HIV status, hence as compared to HIV negative TB patients, HIV positive TB patients were more likely to develop risk of poor treatment outcomes $(\mathrm{AOR}=5.47,95 \% \mathrm{Cl} ; 3.47,8.63)$. This finding was in line with investigations conducted in Ethiopia [21, 35], Somalia [36] South Africa [37], Finland [38] and Brazil [30]. The risk of poor treatment outcomes in TB/HIV co-infected patients could be due to the fact that HIV infection decline CD4 cells count progressively by about $50-80$ cells $/ \mathrm{mm} 3$ per year and hence the immune status the individual might not be efficient enough to prevent the dissemination of Mycobacterium tuberculosis in the body [39]. Also it might be associated to co-administration of ART along with anti-TB therapy, which can lead to drug-drug interactions, overlapping drug toxicities and immune reconstruction syndrome [40].

Residence and treatment outcomes were also highly associated, patients from rural settlement were more likely exposed to poor treatment outcomes as compared to those in urban (AOR $=0.43,95 \% \mathrm{Cl}$ : $0.27,0.67)$. 
The result was in consistent with studies conducted in Southern Ethiopia [15, 41] and Central Ethiopia [42], but in contrary to study conducted in, Southern Ethiopia [43]. As suggested by [41] the lower treatment success in rural residents could be associated with lower awareness of TB treatment and the long distance between their homes and the treatment centers. There was also a significant association between treatment out come and TB type, patients who presented extra pulmonary TB (EPTB) were more likely to risk of poor treatment outcomes as compared to the patients with smear positive (PTB+) and smear negative (PTB-) (AOR $=0.87,95 \% \mathrm{Cl} ; 0.67,1.14)$. The finding was in line with the study conducted in Hossana, South Ethiopia [25], but in contrary with the finding of study conducted in North West Ethiopia [22].

\section{Conclusion}

As the five years retrospective study indicated the DOTS strategy improved TB treatment success in Adare hospital. Treatment outcome rate of registered patients in the study area was high and hasmet the target success rateset by WHO. Residence, HIV status and TB category are main predictors for unsuccessful treatment outcome. Hence, awareness creation through health education for rural patients and regular follow of patients with unsuccessfuloutcome on the wayof treatment is essential.

\section{LIMITATIONS}

A limitation of this study could be that since the data collected is retrospective secondary data and the data source (which was the standard TB register) did not capture detailed information, hence in some cases there was missing and/or inaccurate data. Moreover, the data was collected from one site, Adare Hospital which might not be representative to give general conclusion since patients from other facilities have different profile.

\section{Abbreviations}

AOR Adjusted odds ratio

DOTs Direct observed treatment strategies

EPTB Extra pulmonary TB

FMOH Federal ministry of health

MTBMycobacterium tuberculosis

NTLCPNational tuberculosis and leprosy control program

SNNPR Southern nations nationalities and peoples region

SPSS Statistical package for social science

PTB Pulmonary tuberculosis

TB Tuberculosis 


\section{Declarations}

\section{Ethics}

Institutional ethical clearance was obtained from the ethical Review Committee of Hawassa University. The supportive letter was obtained from Hawassa University and approved by Adare Hospital Medical director office to utilize the retrospective data. Permission to adopt a map of Hawassa city was obtained from Hawassa City dministration.

\section{Authors' contributions}

BT and ZB conceive the idea and developed proposal. BT collected the data, entered the data and conducted data analysis. ZB and SA analyze the data further, interpreted the results and reviewed the initial and final drafts of the paper; finally SA critically reviewed and wrote the manuscript and submited for publishing. All authors read and approved the final manuscript ahead of submitting for publication.

\section{Competing interests}

The authors declare that they have no conflict of interests.

\section{Acknowledgments}

We would like to express our heartfelt gratitude to the Adare Hospital staff in general and Adare Hospital medical director and TB clinic staff in particular for their all-round support during data collection. Our earnest gratitude also goes to Hawassa University for material and technical support during data collection.

\section{Consent for publication}

Not applicable

\section{Availability of data and materials}

All data generated and analysed during the present study are included in this manuscript. However, the overall dataset of this study is not openly accessible because some sensitive information that is forbidden for sharing. However, the data are available from the corresponding author upon reasonable request and with permission from the Adare General Hospital.

\section{References}

1. Patrick OE, Winifred AO. (2009). Success of the Control of Tuberculosis in Nigeria: A Review. International Journal of Health Research; 2:3-14.

2. Santos LC. (2012) The Molecular Basis of Resistance in Mycobaterium tuberculosis. Open J Med Microbio.; 12: $24-36$ 
3. WHO. (2018) Tuberculosiskey facts. Geneva, Switzerland.

4. WHO (2018). Global Tuberculosis report. Geneva, Switzerland.

5. FMOH (2009) TB/ HIV implementation guideline, Addis Ababa, Ethiopia.

6. FMOH. (2008). Tuberculosis, Leprosy and TB/HIV Prevention and Control Program Manual,MOH, Addis Ababa, Ethiopia, 4th edition.

7. FMOH. (2013). TB Research Advisory Committee (TRAC). Road map for Tuberculosis Operational Research in Ethiopia. Addis Ababa, Ethiopia.

8. FMOH (2010) Health Sector Development Programme IV. Addis Ababa, Ethiopia.

9. Belete G, Gobena A, Girmay M, Sibhatu B. (2013). Treatment outcome of tuberculosis patients under directly observed treatment in Addis Ababa, Ethiopia. Braz J Infect Dis.;17:521-528.

10. Belay T, Abebe M, Assegedech B, Dieter R, Frank E, Ulrich S. (2009). Treatment outcome of tuberculosis patients at Gondar University Teaching Hospital, Northwest Ethiopia: A five-year retrospective study. BMC Public Health.; 9:1471-2458.

11. Yassin MA, Datiko DG, Shargie EB. (2006). Ten-year experiences of the tuberculosis control programme in the southern region of Ethiopia. Int J Tuberc Lung Dis;10:1166-1171.

12. Tsegahun A, Moges L, Helen T. (2018). Trends and Treatment Outcomes of Tuberculosis in DebreBerhan Referral Hospital. Ethiopia. Clinical Medicine Research; 7: 97-102

13. FMOH (2013). An Extract of Five Year's TB, TB/HIV AND Leprosy Control Program Analysis. Addis Ababa, Ethiopia.

14. Biruk M, Yimam B, Abrha H, Biruk S, Amdie FZ (2016). Treatment outcomes of tuberculosis and associated factors in an Ethiopian University Hospital. Adv Public Health 2016; 9:10.

15. Gebrezgabiher G, Romha G, Ejeta E, Asebe G, Zemene E, Ameni G. (2016). Treatment Outcome of Tuberculosis Patients under Directly Observed Treatment Short Course and Factors Affecting Outcome in Southern Ethiopia: A Five-YearRetrospectivestudy. PLoSONE11 (2): e0150560.

16. Girum T, Atkure D, Tefera T, Abebe B, Theodros G, Habtamu T, Geremew G, Misrak G, Mengistu T, Minilik D (2018). Treatment Outcome and Associated Factors among TB Patients in Ethiopia: Hospital-Based Retrospective Study. American Journal of Epidemiology and Infectious Disease. 6 : 14-19

17. Getahun A, Haimanot D, Takele T, Gebremedihin G,KetemaT, Gobena A.(2015). Treatment outcome of tuberculosis patients at Gambella Hospital, Southwest Ethiopia: Three-year Retrospective study. J. Infect Dis Ther 3:211. 
18. Mekonnen D, Derbie A, Mekonnen H, Zenebe Y. (2016). Profile and Treatment outcomes of patients with tuberculosis in Northeastern Ethiopia: Across Sectional study. Afri Health Sci; 16: 663-670.

19. WHO. 2014. Global tuberculosis Report Geneva, Switzerland.

20. FMOH (2012). Ethiopia Federal Ministry of Health Guidelines for clinical and programmatic

Management of TB and Leprosy and TB/HIV in Ethiopia. Fifth edition. Addis Abeba

21. Gebretsadik B, Fikre E and Abreham A.(2012). Treatment outcome of smear-Positive Pulmonary Tuberculosis Patients in Tigray Region, Northern Ethiopia. BMC Public Health, 2012; 12:1471-2458.

22. Endris M, Moges F, BelyhunY, Woldehana E, Esmael A, Unakal C. (2014). Treatment Outcome of tuberculosis patients at Enfraz health Center, northwest ethiopia: a five-year retrospective study. Tuberc Res Treat,(726193):5.

23. Sisay S, Mengistu B, Erku W, Woldeyohannes D. (2014). Directly Observed Treatment Short-course (DOTS) for tuberculosis control program in Gambella Regional State, Ethiopia: ten years experience. BMC Res Notes.;7:1756-0500

24. Ejeta E, Chla M, AregaG, Ayalsew K, Tesfaye L, Birhanu T, Disassa H. (2015). Treatment outcome of Tuberculosis patientsUnder Directly Observed Treatment of Short Course in Nekemt Town, WesternEthiopia: Retrospective Cohort Study. Gen Med 3:1000176.

25. Tigist M, Kidist D, Degefa H and Taye L. (2016). Treatment outcomes of tuberculosis patients in NigistEleni Mohammed General Hospital, Hosanna, South Ethiopia, a five year retrospective study. Archives of Public Health 201775:16.

26. Ramya A, Kaliyaperumal K and Marimuthu G.(2013). The profile and treatment outcomes of the older (aged 60 years and above) tuberculosis patients in Tamilnadu, South India.PLoS One,1371; 8(7).

27. Duru CB, Uwakwe KA,Nnebue CC, Diwe KC, Merenu IA,Emerole CO, Iwu CA and Duru, CA. (2016).Tuberculosis treatment outcomes and determinants among patients treated in hospitals in Imo state, Nigeria.Libr J. 3:e2754.

28. Gabida M, Tshimanga M, Chemhuru M, Gombe N, Bangure D (2015). Trends for tuberculosis treatment outcomes, New sputum smear positive patients in kwekwe district, Zimbabwe, 2007-2011: a cohort analysis. J Tuberc Res.3:126-35.

29. Aysun S, Aka A, Yusuf A, Nurullah K, Nagihan K and Fatma, T. (2015). Factors affecting successful treatment outcomes in pulmonary tuberculosis: a single-center experience in Turkey, 2005-2011. J Infect DevCtries.; 9:821-8.

30. Mariade F, Pessoa M, Albuquerque R, Arraes de A, Ximenes N and Lucena-Silva, W. (2007). Factors associated with treatment failure, Dropout and death in a cohort of tuberculosis patients (from May 2001 to July 2003) in Recife, Pernambuco State, Brazil. Cad SaudePublica. 23:1573-82. 
31. Gadoev J, Asadov D, Tillashaykhov M, Tayler-Smith K, Isaakidis P, Dadu,A, de Colombani P, Hinderaker SG,Parpieva N,Jalolov A,Hamraev A.(2015). Factors associated with unfavorable treatment outcomes in new and previously treated TB patients in Uzbekistan: a five year countrywide study. PLoSOne10: e0128907.10.1371

32. Firdie T, Tariku D and Tsegaye T. (2016). Treatment outcomes of TB patients at DebreBerhan Hospital, Amahara Region, North Ethiopia. Ethiop J Health Sci. 26: 65-72.

33. Nik N, Ronaidi NM, Mohd NS, WanMohammad Z, Sharina D and Nik R NH. (2011). Factors associated with unsuccessful treatment outcome of pulmonary tuberculosis in Kotabharu, Kelantan: A retrospective cohort study. Malays J Public Health Med. 11:6-15.

34. Addisu M, Balew Z, Biniam E.(2016). Treatment outcome and Associated Factors among Tuberculosis Patients in Debre Tabor, North Ethiopia: A Retrospective Study. Tuberc Res Treat.: 1354356.

35. Ketema T, Teresa K, Adugna A, Geremew T, Shimelis M, Solomon S, Legesse T, andGilman KHS. (2018). Treatment Outcomes of Tuberculosis at Asella Teaching Hospital, Ethiopia: Ten Years' Retrospective Aggregated Data. Front Med (Lausanne); 5: 38.

36. Ali MK, Karanja S, Karama M.( 2017). Factors associated with tuberculosis treatment outcomes among tuberculosis patients attending tuberculosis treatment centers in 2016-2017 in Mogadishu, Somalia. Pan African Medical Journal.28:197.

37. Padmapriyadarsini, C., Narendran, G and Swaminathan, S. (2011).Dignosis and Treatment of Tuberculosis in HIV co-infected patients. Indian J Med Res. 134:850-865.

38. Seddon JA, Hesseling AC, Willemse M, Donald PR, Schaaf HS (2012). Culture-confirmed multidrugresistant tuberculosis in children: clinical features, treatment and outcome. Clinical infectious diseases. 54: 157-166.

39. Havlir DV, Getahun H, Sanne I, Nunn P. (2008). Opportunities and challenges for HIV care in overlapping HIV and TB epidemics. JAMA.; 300(4): 423-430.

40. Vasankari T, Holmström P, Ollgren J, Liippo K, Kokki M, Ruutu P (2007). Risk factors for poor tuberculosis treatment outcome in Finland: a cohort study. BMC public health. 7: 291.

41. Ramose JM, Reyes F and Facin R. (2008). Surgical lymph biopsies in a rural Ethiopian hospital: histopathologic diagnoses and clinical characteristics. Ethiop Med J. 46:173-178.

42. Ayeno HD, Regasa BM, Lenjisa JL, Umeta GT, Woldu MA. (2014). A three Years Tuberculosis Treatment OutCome at Adama Hospital of Medical College, South East Ethiopia, A retrospective cross-sectional analysis: IJPBS. 2: 2347-4785.

43. Mesay HD, Daniel GD, Bernt L. (2014). Trends of tuberculosis case notification and treatment outcomes in the Sidama Zone, Southern Ethiopia: ten-year retrospective trend analysis in urban-rural settings. PLoS One9:1-18.10.1371 


\section{Tables}

Due to technical limitations, Table(s) 1 and 4 are only available as a download in the supplemental files section.

Table 2: Tuberculosis treatment outcomes by demographic and profile of TB patients in Adare Hospital, South Ethiopia, from 2013-2017.

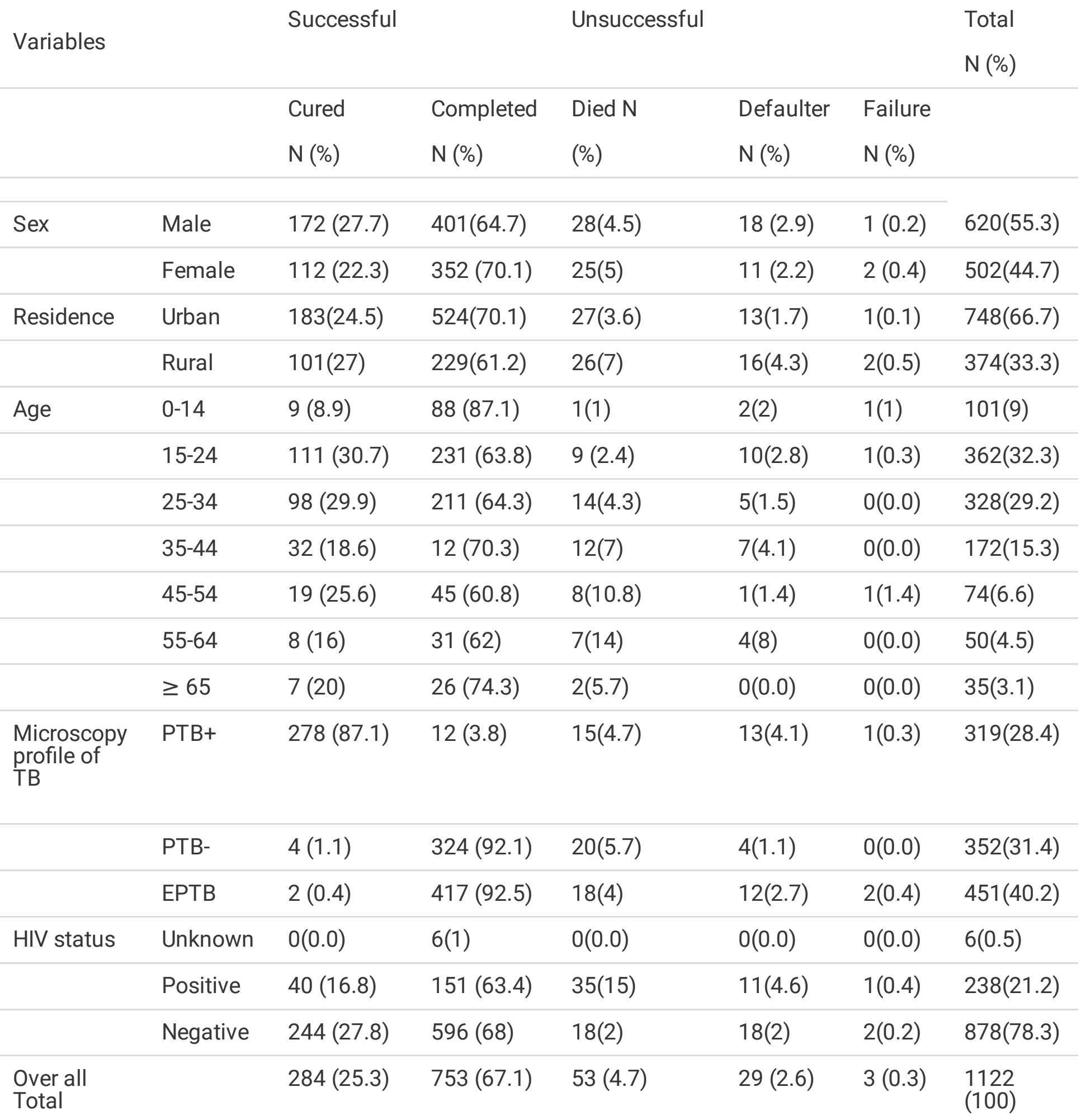


Table 3. Trend of treatment outcome of all form of registered TB cases $(n=1122)$ in Adare Hospital, South Ethiopia, from 2013 to 2017.

\begin{tabular}{|c|c|c|c|c|c|c|}
\hline \multirow{2}{*}{$\begin{array}{l}\text { Treatment } \\
\text { outcome }\end{array}$} & \multicolumn{5}{|l|}{ Year } & \multirow{2}{*}{ Total (\%) } \\
\hline & 2013 & 2014 & 2015 & 2016 & 2017 & \\
\hline Cured (\%) & $50(20.8 \%)$ & $97(26.8 \%)$ & $67(23.6 \%)$ & $57(30 \%)$ & $13(33.3 \%)$ & $284(25.3)$ \\
\hline $\begin{array}{l}\text { Treatment } \\
\text { completed (\%) }\end{array}$ & $183(76.3 \%)$ & $242(66.9 \%)$ & $197(67.7 \%)$ & $110(57.8 \%)$ & $21(53.8 \%)$ & $753(67.1)$ \\
\hline Successful & 233 (97\%) & $339(93.6 \%)$ & $264(90.7 \%)$ & $167(87.9 \%)$ & $34(87.2 \%)$ & $1037(92.4)$ \\
\hline \multicolumn{7}{|l|}{ Total (\%) } \\
\hline Died (\%) & $6(2.5 \%)$ & $9(2.5 \%)$ & $19(6.5 \%)$ & $15(7.9 \%)$ & $4(10.3 \%)$ & $53(4.7)$ \\
\hline Defaulter (\%) & $1(0.4 \%)$ & $13(3.6 \%)$ & $6(2.1 \%)$ & $8(4.2 \%)$ & $1(2.6 \%)$ & $29(2.6)$ \\
\hline $\begin{array}{l}\text { Treatment } \\
\text { Failure (\%) }\end{array}$ & $0(0.0)$ & $1(0.3 \%)$ & $2(0.7 \%)$ & $0(0.0)$ & $0(0.0)$ & $3(0.3)$ \\
\hline $\begin{array}{l}\text { Unsuccessful } \\
\text { Total (\%) }\end{array}$ & 7 (2.9\%) & $23(6.4 \%)$ & $27(9.3 \%)$ & $23(12.1 \%)$ & $5(12.8 \%)$ & $85(7.6)$ \\
\hline Over all Total (\%) & $240(21.4)$ & $362(32.3)$ & $291(25.9)$ & $190(16.9)$ & $39(3.5)$ & $1122(100)$ \\
\hline
\end{tabular}

\section{Figures}




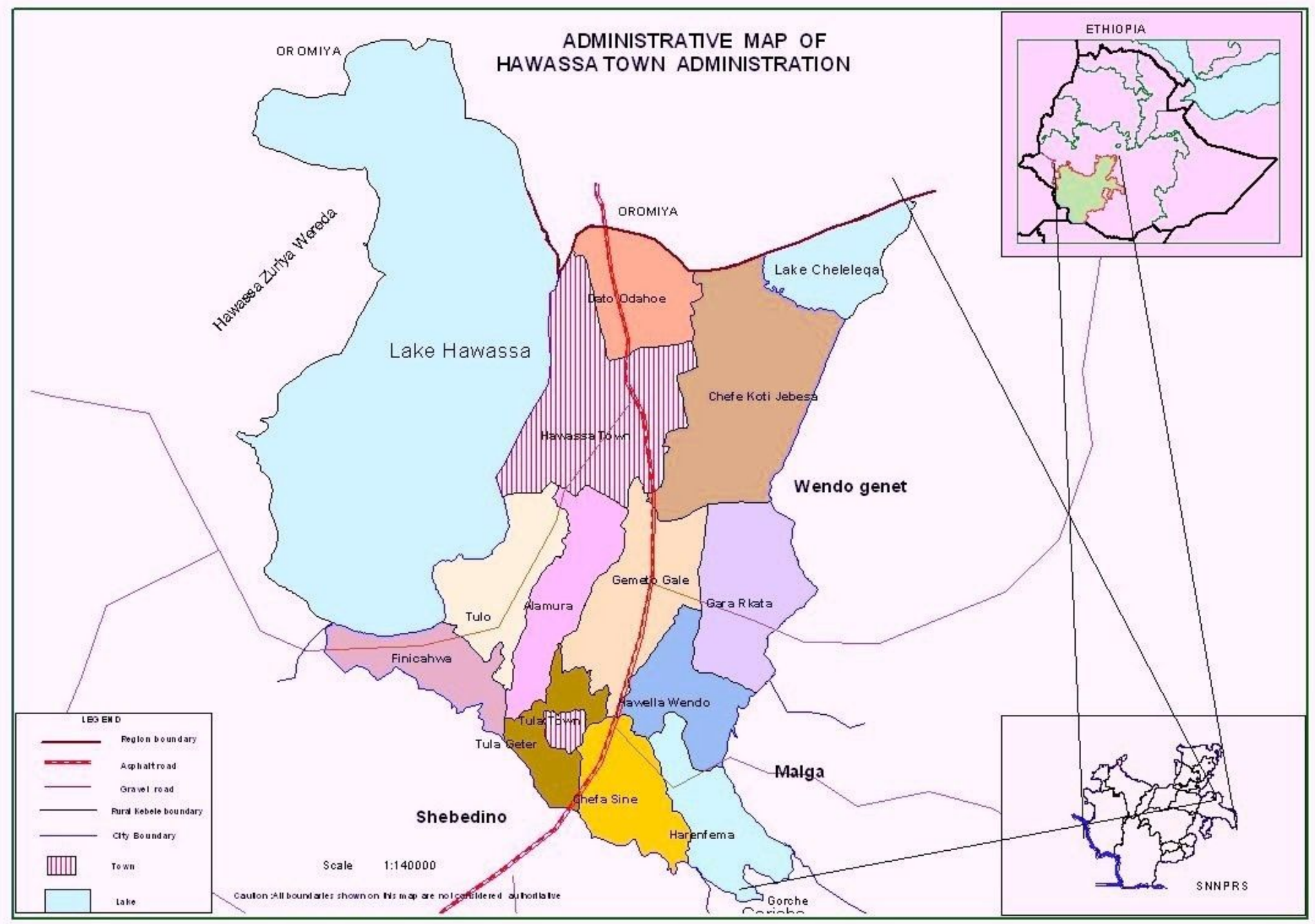

Figure 1

Map of the study area (Source Hawassa city Administration)

\section{Supplementary Files}

This is a list of supplementary files associated with this preprint. Click to download.

- supplement1.pdf

- supplement2.pdf 